\title{
Abundance and Distribution of Freshwater Eels in Pangi River, Maitum, Sarangani Province \\ Valdez ASM* and Castillo TR
}

Mindanao State University, General Santos City, Philippines

\begin{abstract}
A study on the abundance and distribution of Freshwater Eels was conducted in Pangi River, Maitum Sarangani Province. Three stations, 50 meters away from each other, were set starting at the mouth of the river with coordinates $06.02278^{\circ} \mathrm{N}, 124.52069^{\circ}$. In every station are three substations at the right side near the bank, at the center and at the left side near the bank. The study was done from a period of 5 months starting from October 2014 to February 2015. Sampling was done every Full moon and New moon of the month during the low tide and high tide fluctuation. Salinity and temperature were also monitored during sampling.

The freshwater eels were identified using morphological characteristics. A total of 4,262 individuals had been collected for five (5) months of sampling, Freshwater eels were found abundant during new moon with a total of 4,249 individuals and only 13 individuals were collected during full moon.

Results showed that two species of Freshwater eels has been observed on the area out of 18 species of Freshwater Eels, the Anguilla marmorata and the Aguilla bicolor pacifica. The study further showed that the Anguilla marmorata is most abundant with abundance index of $96.62 \%$, frequency index of $100 \%$ and dominance index of $196.62 \%$, while Anguilla bicolor pacifica had the abundance index of $3.26 \%$, frequency index of $42.86 \%$ and dominance index of $46.12 \%$.

There are two types of bottom substrates observed in the area Station 1 had sandy while Station 2 and 3 had rocky substrate. Anguilla marmorata is more often seen in the rocky bottom since they prefer to hide under the rocks and gravely bottom.

Catch per unit effort (CPUE) was computed to range from $0.075 \mathrm{gm} /$ hour to $500 \mathrm{gm} / \mathrm{hour}$. Temperature was monitored to be within the range of $23^{\circ} \mathrm{C}-25^{\circ} \mathrm{C}$ for the entire sampling period.

Further study is recommended to monitor the freshwater eels that migrating upstream the river of Pangi, Maitum, Sarangani Province, beyond Station 3.
\end{abstract}

Keywords: Abundance; Distribution; Eels; Pangi river

\section{Introduction}

Eel is the common name for any fish of the 10 families constituting the Order Anguilliformes, it is characterized by a long snakelike body covered with minute scales embedded in the skin. Eels lack the hind parts of fins, adapting them for wriggling in the mud and through the crevices of reefs and rocky stones.

According to Schrank in year 1798, freshwater eels are catadromous, that spawns in tropical ocean waters, and has a peculiar leptocephalus larval stage that is unique to elopomorph fish. They constitute a single Genus, Anguilla.

The fishing for freshwater eels, along with environmental pollution and other human impacts, have all contributed to a significant decline in eel numbers over the last 25-30 years. Total volume of glass eels collected on an annual basis is around 150 tonnes which satisfies the current aquaculture needs of approximately 100 tonnes/year with the excess going to human consumption in Spain [1]. Many people are involved in the eel collection, transportation and distribution, from glass eel fishers to the eel farmer and processor [1].

In the Philippines, freshwater eels have different populations scattered in various regions in country in which they are considered important food fish especially to the indigenous people [2]. There has been documented on the evolutionary history and phylogenetic studies of the eels in the country and by traditional molecular methods, where this fishes are quite abundant and geographically near to their spawning ground [2]. Knowledge and background of the natural life history and specification are the basis for sound fishery management or aquaculture industry development of eels.

The study provides baseline information on the abundance and distribution of the freshwater eels that present in Pangi River Maitum, Sarangani Province. This serves as basis for action plan of the Local and National Government Unit for protection and conservation of Freshwater Eels in the area [3-10].

\section{Materials and Methods}

\section{Sampling area and sampling stations}

Pangi River can be found at Brgy. Pangi, Maitum, Sarangani Province (Figure 1). The sampling stations stretch from 50 to 100 meters which is further subdivided into tree substations, where two (2)

*Corresponding author: Valdez ASM, Mindanao State University, General Santos City, Philippines, Tel: +6363 3521002; E-mail: enairashane.zedlav@yahoo.com.ph

Received October 29, 2015; Accepted December 30, 2015; Published February 15,2016

Citation: Valdez ASM, Castillo TR (2016) Abundance and Distribution of Freshwater Eels in Pangi River, Maitum, Sarangani Province. J Aquac Res Development. 7: 410. doi:10.4172/2155-9546.1000410

Copyright: $\odot 2016$ Valdez ASM, et al. This is an open-access article distributed under the terms of the Creative Commons Attribution License, which permits unrestricted use, distribution, and reproduction in any medium, provided the original author and source are credited. 
Citation: Valdez ASM, Castillo TR (2016) Abundance and Distribution of Freshwater Eels in Pangi River, Maitum, Sarangani Province. J Aquac Res Development. 7: 410. doi:10.4172/2155-9546.1000410

is designated at both sides and 1 substation at the center.

There are two (2) types of substrates observed in the area: sandy and rocky. The mouth of the river or the station 1 had its sandy bottom while the station 2 and 3 had its rocky bottom.

The Sampling Stations will be as follows:

Station 1-at the mouth of the river with the coordinates of $06.02278^{\circ}$ $\mathrm{N}, 124.52069^{\circ} \mathrm{E}$

Substation 1: at the right side near the bank

Substation 2: at the center

Substation 3: at the left side near the bank

Station 2-50 meters ahead from the station 1 with the coordinates of $06.02435^{\circ} \mathrm{N}, 124.52196^{\circ} \mathrm{E}$

Substation 1: at the right side near the bank

Substation 2: at the center

Substation 3: at the left side near the bank

Station 3-100 meters ahead from the station 1 with the coordinates of $06.02479^{\circ} \mathrm{N}, 124.52287^{\circ} \mathrm{E}$

Substation 1: at the right side of the bank

Substation 2: at the center

Substation 3: at the left side near the bank

The first substation is placed on the mouth of the river which expands from 31 meters at low tide to 100 meters up at high tide. The second station will be 50 meters away from the mouth of the river, the third station is 50 meters away from the second station.

\section{Sampling methods and sampling frequency}

Sampling is done by collecting the anguillid eels that is trapped using net traps as collecting gear on the $1^{\text {st }}, 2^{\text {nd }}$ station and $3^{\text {rd }}$ station. This is made of 8 meters mosquito net, rope and bamboo sticks. A set of three net traps are set together in three stations to intercept as many as possible eels over a wide area. The net traps are set in the afternoon and timed by the incoming high tide and get the trapped glass eels using the (sigpaw) Scoop net.

Sampling is done every full moon and new moon of the month to observe the tidal fluctuation in collecting freshwater eels.

\section{Data collection}

The information that are noted and gathered during sampling is the following:

- Date and time of sampling

- Length of fishing period

- Water parameters like temperature, salinity

- Biomass of animals caught

- Morphometric measurements of elvers and adults that will be collected.

The eels that will be collected will be identified through its morphological characteristics.

Determining the species using morphological characteristics (Figure 2).

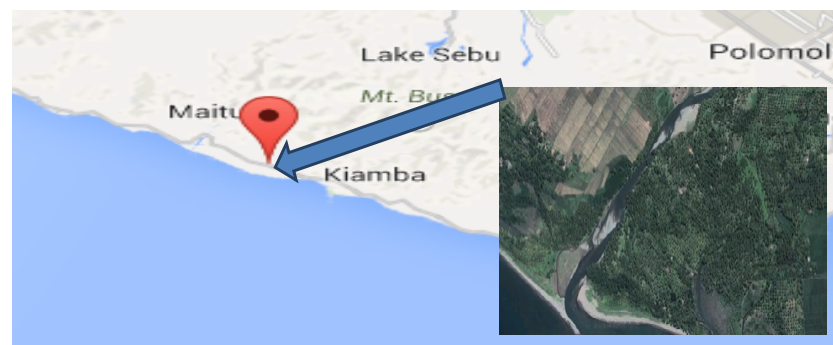

Figure 1: Maitum, Sarangani Map.

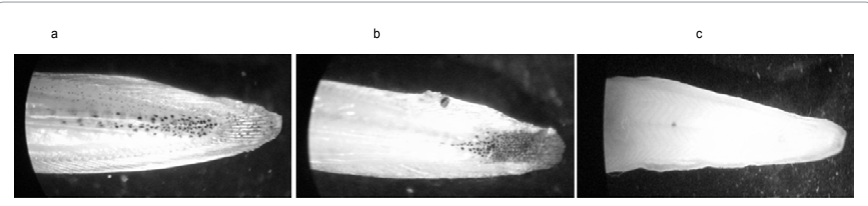

Figure 2: Morphological chracteristics of glass eel species showing the tail bud and caudal fin cutaneous pigmentation patterns;(a) Anguilla marmorata and/or Anguilla luzonensis (b) Anguilla bicolorpacifica (c) Anguilla japonica.

The following data are computed using the information gathered during sampling:

Catch per unit effort

The information on biomass of animals caught and length of fishing are used to compute for the Catch per unit effort using the formula:

$$
\begin{aligned}
& \text { CPUE }(g / \text { hour })=\frac{(\text { Total weight of } \text { catch })}{(\text { No. of hour } \text { in catching })} \\
& \text { Abundance Index }=\frac{\text { Total no. of particular species }}{\text { Total } \text { no. of all species }} \times 100 \\
& \text { Frequency Index }=\frac{\text { No. of sampling the particular species found }}{\text { Total no. of sampling }} \times 100
\end{aligned}
$$

Dominance Index $=$ Abundance Index + Frequency Index

The Collected anguillid eels were fixed in 95\% ethanol alcohol just after weighing and the specimens were counted.

\section{Results and Discussion}

Results showed that there are two types of Freshwater eels which can be found on Pangi River, Maitum Sarangani Province those are the Anguilla marmorata species and the Anguilla bicolor pacifica. A total of 4,262 individuals were collected and a total Catch per unit effort of $65.98 \mathrm{~g} / \mathrm{hr}$ for the duration of five (5) months for the month of October-February (2014-2015). The Anguilla marmorata species are the highly observed in the area of sampling with the total number of 4,118 individuals out of the 4,262 individual collected for five (5) months. It had an Abundance Index of $96.62 \%$, Frequency Index 100\% and Dominance Index 196.62 and the Anguilla bicolor pacifica species with the total number of 139 individuals, had an Abundance Index of $3.26 \%$, Frequency Index $42.86 \%$, and Dominance Index of 46.12 (Figure 3).

The largest catches of the freshwater eels were in the month of November during the New Moon phase and with the zero catches during the month of December and January Full moon. It is also showed that on the station 2, substation 1 right side near the bank is more applicable area on setting the trap than station 1 and station 3 , since the water depth and current is more severe on the area of Station 
Citation: Valdez ASM, Castillo TR (2016) Abundance and Distribution of Freshwater Eels in Pangi River, Maitum, Sarangani Province. J Aquac Res Development. 7: 410. doi:10.4172/2155-9546.1000410

1 and Station 3. As well as visual observation indicated that glass eels were most abundant on the side of the river bank. The trap which is placed in station 1 which is found on the mouth of the river had been destroyed by the waves due to the strong winds and drifted trees during sampling, and for the trap which is set on the center of the station 1 is not comfortable for the collector and trap due to the high level of the water that occur on the center of the river during high tide it reaches 10 to 20 feet depth at the center of the river. While on station 3 it is hard to set the trap since station 3 possesses larger rocks and also not suitable for the traps due to the strong current coming from the upstream of the river, it gives damage to the net trap. Data also shows that freshwater eels is more abundant during the new moon phase than the full moon phase, due to the moon light which is present every full moon, freshwater eels is more seen during dark hours such as new moon, glass eels prefer to migrate during those times, suggesting that the lunar phase has a strong effect on inshore migration mechanism of glass eel at the mouth of the Pangi River, there were 4,249 individuals collected caught during the new moon samples obtained in five (5) months (from 2014-2015) used for comparison during the full moon phase which are 13 individuals collected during those times. Weather condition also had been noted and observed during the sampling period (Figures 4 and 5).

Temperature is also a factor that affects the migration of Freshwater Eels they are more likely to stay on colder part of the river which is more observed on the study, they prefer to migrate upstream. Other study also who has been conducted on other countries said that temperature affects the survival of the Freshwater eels (Figure 6).

\section{Abundance, frequency, and dominance of freshwater eels in Pangi river}

The following Figures 7-9 showed that Anguilla marmorata is the

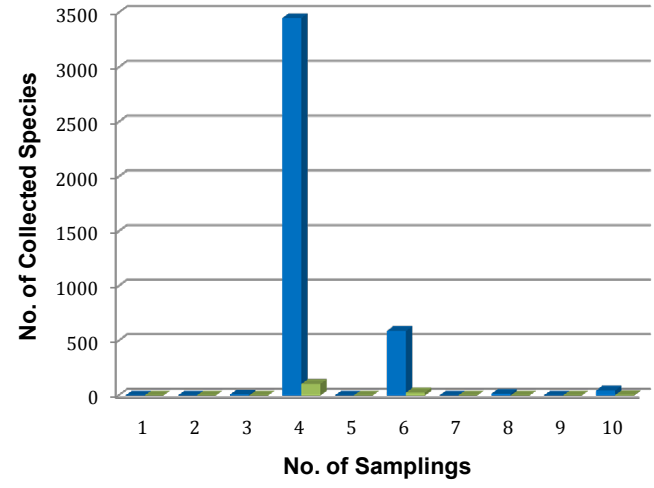

A. marmorata A. bicolor pacifica

Figure 3: Collected species.

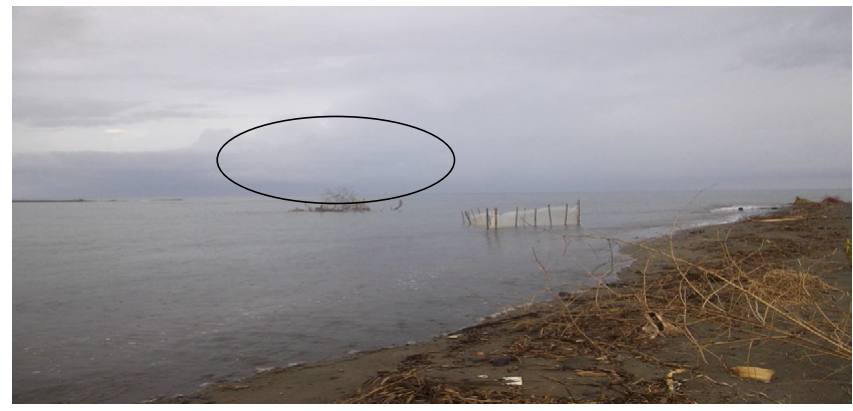

Figure 4: Station 1 destroyed by the waves and drifted trees.

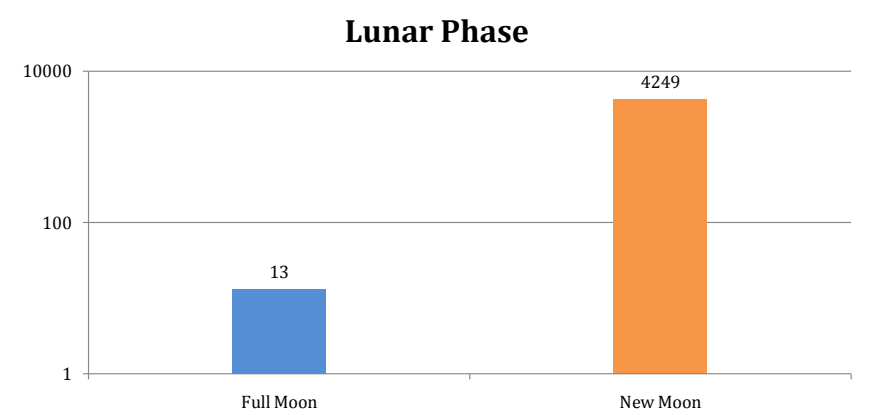

Figure 5: Lunar phase.

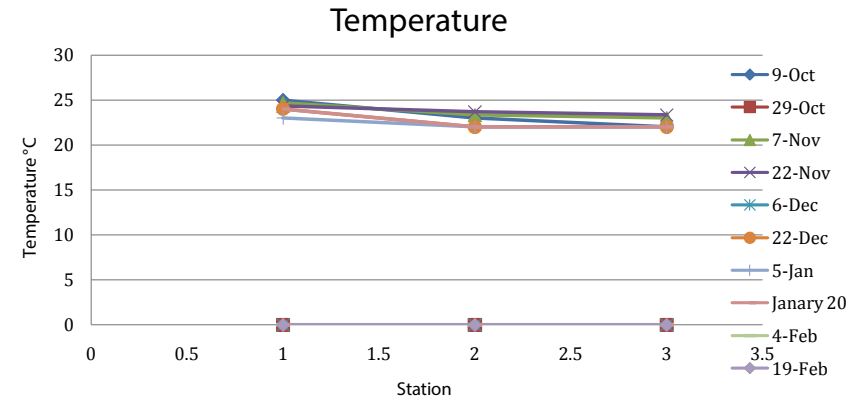

Figure 6: Temperature

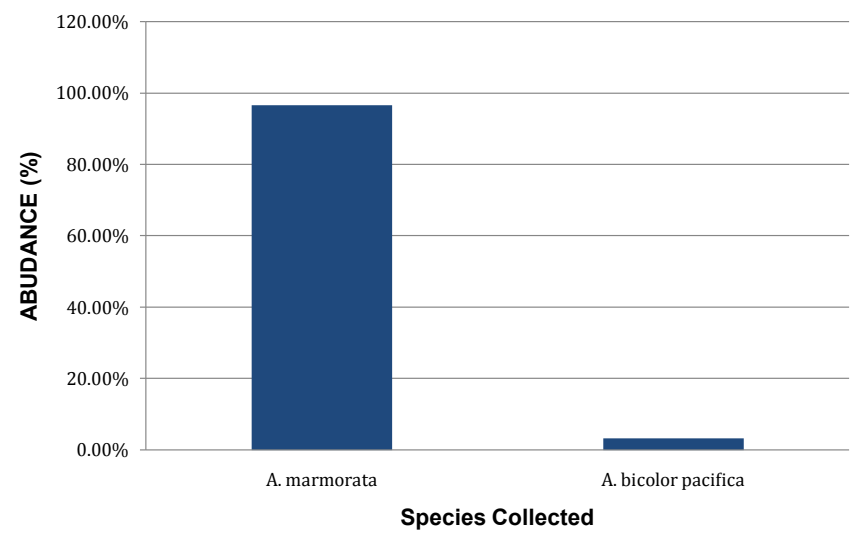

Figure 7: Abundance of collected freshwater eels.

most abundant, frequent, and dominant species of freshwater eels that can be found in the area.

In terms of abundance A. marmorata has an average of $96.62 \%$, while the A. bicolor pacifica has an average of $3.26 \%$. This could be attributed to their habitat and migration pathways as mentioned earlier.

In terms of frequency, A. marmorata has an average of $100 \%$, while A. bicolor pacifica has an average of $42.86 \%$.

In terms of Dominance, A. marmorata has an average of 196.62, while A. bicolor pacifica has an average of 46.12 .

Table 1 represents the abundance, frequency and dominance of the two species that has been collected on the study as general. 
Citation: Valdez ASM, Castillo TR (2016) Abundance and Distribution of Freshwater Eels in Pangi River, Maitum, Sarangani Province. J Aquac Res Development. 7: 410. doi:10.4172/2155-9546.1000410

Page 4 of 4

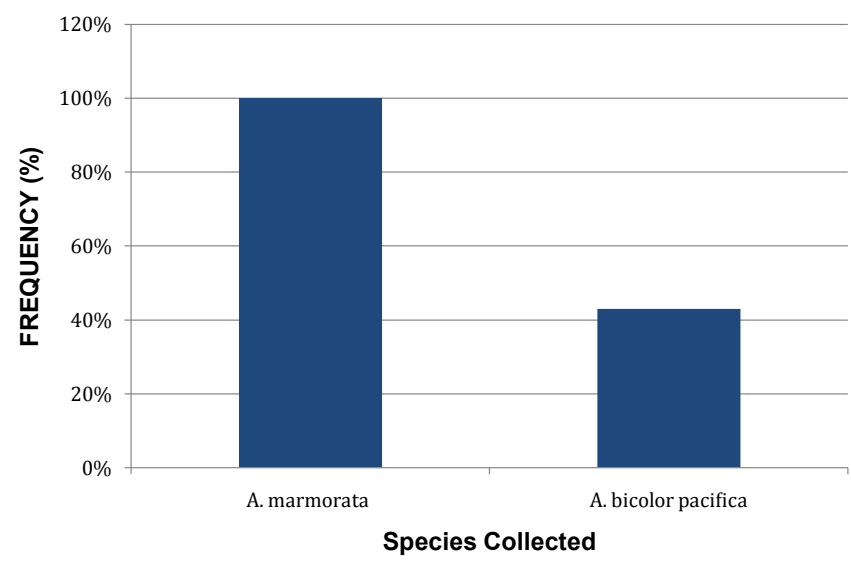

Figure 8: Frequency of collected freshwater Eels.

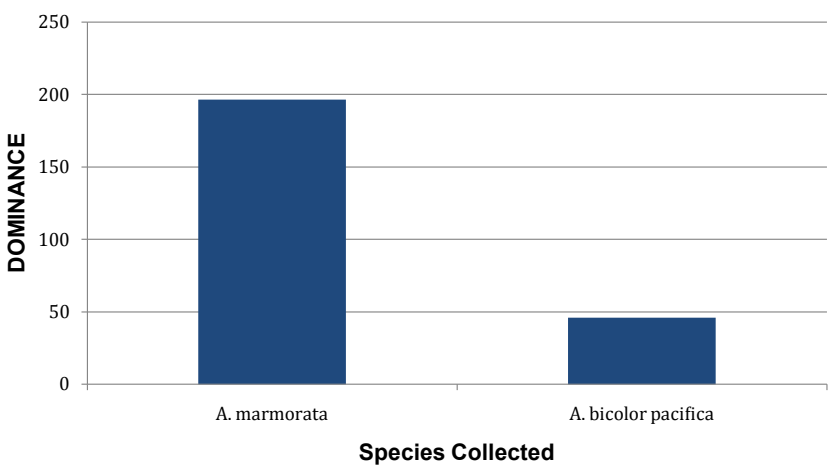

Figure 9: Dominance of collected freshwater Eels.

\begin{tabular}{|l|c|c|c|c|}
\hline Species collected & $\begin{array}{c}\text { Abundance } \\
\text { (\%) }\end{array}$ & Frequency (\%) & Dominance & $\begin{array}{c}\text { No. of } \\
\text { individual }\end{array}$ \\
\hline A. marmorata & $96.62 \%$ & $100 \%$ & 196.62 & 4,118 \\
\hline A. bicolor pacifica & $3.26 \%$ & $42.86 \%$ & 46.12 & 139 \\
\hline
\end{tabular}

Table 1: Table presenting the abundance, frequency ad dominance of the collected freshwater eels.

\section{Conclusion and Recommendation}

The Abundance and Distribution of Freshwater Eels in the area of Pangi River, Maitum Sarangani Province revealed that the river had its source for wild eels especially the Anguilla marmorata species that suits for culturing process in the near future, since the river possesses a rocky substrate which is good for the habitat of the said species. In conclusion the findings of this study confirm that there are two species which are present on the Pangi River which is the Anguilla marmorata and Anguilla bicolor pacifica, the good quality of the water and maintaining its cleanliness is another key factor why those wild eels keep on migrating on the area, due also to the abundance of other food that can be found on the area.

Studies in the laboratory or with different types of sampling gear fished in the Pangi River itself will be helpful to further examine the abundance and distribution of freshwater eels in Pangi River, Maitum Sarangani Province.

\section{Acknowledgement}

The researcher would like to dedicate her work to those who shared their support and guidance.

To her adviser, Prof. Tersa R. Castillo for the time and supervision, for the significant ideas she had contributed for the success of the study.

To the members of the defense panel, Prof. Glennville A. Castrence and Prof. Ronald $P$. Sombero for their suggestions and contributions for the best outcome of the study. To Dr. Apolinario A. Yambot for the knowledge he had shared and for his time and guidance throughout the study.

The researcher would like to express her gratitude to Mr. Rey Bonrustro a.k.a uncle illing, Bon Bon, Jannet and Chikoy for the assistance, to her friends, Julius Jacob, Katelyn, KH Family, and classmates, CFC-Youth for Christ and MBH family for giving her moral support you have made this experience exceptional.

All of these are impossible without her parents Mr Allan A. Valdez and Mrs Ailen M. Valdez, to his siblings Ezra and Dwin and her special someone Rein who had been her inspiration to finish this study.

And lastly, she is most grateful to the Almighty God, for He made all this work in order. Thank you.

\section{References}

1. Nielsen T, Prouzet $P$ (2008) Capture-based aquaculture of the wild European eel (Anguilla anguilla). In: Lovatelli A, Holthus PF (eds). Capture-based aquaculture. Global overview. FAO Fisheries Technical Paper. No. 508. Rome, FAO.

2. Jamandre BWD, Shen KN, Yambot AV, Tzeng WN (2007) Molecular phylogeny of Philippine freshwater eels Anguilla spp. (Actinopterygi: Anguilliformes: Anguillidae) inferred from mitochondrial DNA. Raffles Bull Zool 14: 51-59.

3. Yambot AV (2007) Determining the species of glass eels. Molecular Biology and Biotechnology Laboratory College of Fisheries, Central Luzon State University.

4. Ege V (1939) A revision of the genus Anguilla Shaw, a systematics, phylogenetic and geographical study. Dana Rep 16: 1-256.

5. Miller MJ, Tsukamoto K (2004) The worldwide distribution of anguillid leptocephali. In: Aida K, Tsukamoto K, Yamauchi K (eds). Eel Biology. Springer Verlag, Tokyo.

6. Rellon LP (2013) Classification of Pangi River. Program for Public Hearing.

7. Tzeng WN (1985) Immigration timing and activity rhythms of the eel Anguilla japonica elvers in the estuary of northern Taiwan, with emphasis on environmental influences. Bull Jap Soc Fish Oceanography 47: 11-28.

8. Tzeng WN (2004) Modern Research on the natural life history of the Japanese eel Anguilla japonica. Journal of the Fisheries Society of Taiwan 31: 8-39.

9. Tsukamoto K, Arai T (2001) Facultative catadromy of the eel Anguilla japonica between freshwater and seawater habitats. Mar Ecol Prog Ser 220: 265-276.

10. Watanabe S, Aoyama J, Tsukamoto K (2009) A new species of freshwater eel Anguilla luzonensis (Teleostei: Anguillidae) from Luzon Island of the Philippines. Fisheries Science 75: 387-392. 